EESTI NSV TEADUSTE AKADEEMIA TOIMETISED. X KOIDE FOOSIKALIS-MATEMAATILISTE JA TEHNILISTE TEADUSTE SEERIA, 1961, NR. 3

ИЗВЕСТИЯ АКАДЕМИИ НАУК ЭСТОНСКОЙ ССР. ТОМ Х СЕРИЯ ФИЗИКО-МАТЕМАТИЧЕСКИХ И ТЕХНИЧЕСКИХ НАУК. 1961, № 3

\title{
ДЕСТРУКЦИЯ СЛАНЦА-КУКЕРСИТА ПОД ВОЗДЕЙСТВИЕМ ИСК.РОВОГО РАЗРЯДА В ЖИДКОЙ СРЕДЕ
}

\author{
М. Я. ГУБЕРГРИЦ, Б. Х. БРОДСКАЯ, Л. П. ПААЛЬМЕ, \\ кандидаты технических наук
}

\section{К. А. КУив}

Предыдущие работы авторов $\left[{ }^{1-4}\right]$ показали, что принципиальным пороком процесса термического разложения сланца-кукерсита является невозможность устранения и даже существенного ограничения термоннициируемых вторичных реакций уплотнения и поликонденсацин. Неизбежным их результатом является значительный выход тяжелых конденсированных продуктов (тяжелая смола, кокс), непригодных для химического использования.

Целесообразным путем более полного использования кукерсита представляется активированная его деструкция при сравнительно низкой температуре или чрезвычайно кратковременном воздействин высокой температуры. Продукты такой деструкции должны явиться интересным объектом для органического синтеза. В настоящей статье в сжатом виде изложены основные результаты первого этапа проведенных в этом направлении исследований, имевших целью выбор соответствующего энергоносителя и прннципиальную оценку его воздействия на кероген сланца.

\section{Выбор энергоносителя}

Одним из энергоносителей, действие которых на органические соединения в настоящее время изучается, является поток так называемых быстрых частиц (радиоактивное и другие ионизирующие излучения). Экспериментальные данные по радиолизу углеводородов нефти приводят к заключению, что наиболее эффективным с технической точки зрения является все же сочетание радиолиза с термическим воздействием - радиотермический крекинг. В результате теоретической обработки материалов по радиолизу углеводородов установлено *, что для их активированной деструкции не обязательно прибегать к облучению частицами, обладающими высокой энергией. В ряде случаев достаточно воздействие так называемых медленных частиц с надтепловой энергией.

Воздействие же ионизирующих излучений на синтетические и природные полимеры [5] зависит от структуры исходного мономера и свойств полимера в целом. В известных случаях оно вызывает деструкцию последнего, в других - сшивание полимерных цепочеқ и уплотнение материала. Возможен и промежуточный вариант сочетание обоих процессов.

Ряд работ свидетельствует о том, что инициатором деструкции или полимеризации является другой энергоноситель - ультразвуковые волны большой интенсивности, в частности, благодаря ударно-кавитационному эффекту [']. Известное из литературы $\left[{ }^{7},{ }^{8}\right]$ применение высокочастотного электрического поля (частота около $30 \mathrm{мгц)} \mathrm{для}$ обработки таких природных высокомолекулярных веществ, как угли, приводит в конечном счете к их термическому разложению.

* Доклад Л. С. Полака на II Всесоюзном совещании по радиационной химии в октябре 1960 г. 
Представляют интерес методы высокоскоростной деструкции веществ при кратковременном воздействии температуры, превышающей $2000-3000^{\circ} \mathrm{C}\left[{ }^{\circ}\right]$. Практическое же нх использование связано со значительными техническими трудностями при подборе термостойких материалов и способов нагрева.

Прнведенный краткий обзор позволяет остановиться на процессе деструкции сланца за счет энергии, выделяющейся при искровом разряде высокого напряжения в жидкой диэлектрической среде. При этом методе, как будет показано ниже, сочетаются ссновные достоинства перечисленных выше энергоносителей без их специфических недостатков. Предыдущими экспериментами одного из авторов $[10,11]$ показано, что действие электрических импульсов высокого напряжения непосредственно на целик кукерсита, представляющий собой своеобразный полупроводник, в зависимости от выбранных параметров является либо чересчур локализованным (местный волосной пробой с прожигом), либо слишком рассредоточенным (растрескивание и механическое разрушение). Поэтому целесообразнее использовать для деструкции энергию, выделяющуюся при пробое жидкого диэлектрика - наилучшего передатчика ударноволнового воздействия ко взвешенным частицам сланца. В работах других исследователей этот принцип использован для механического разрушения твердых тел $\left[{ }^{12}\right]$, а также для выделения некоторых минеральных компонентов -угля [ $\left.{ }^{13}\right]$.

Применение его для деструкции органического вещества сланца связано с периоднческим воздействием на кероген трех основных факторов: 1) ударно-квзрывного» и кавитационного эффекта значительной силы; 2) весьма высокого температурного потенциала (температура в искровом разряде достигает 20-40 тысяч градусов [ $\left.{ }^{14}\right]$ ) в чрезвычайно короткие, исчисляемые мнкросекундами промежутки времени; 3) лавинообразного потока заряженных частиц с надтепловой энергией. Сфера действия двух последних факторов ограничирается непосредственно зоной искрового разряда, а первого из них - распространяется на более значительный реакционный объем. Вероятность попадания взвешенных частиц сланца в зону искрового разряда может быть соответственно повышена или снижена в зависимости от предъявляемых к процессу требований.

Использование в качестве вмещающей среды и передатчика энергии жидкости со сравнительно большими теплоемкостью и скрытой теплотой испарения, а также интенсивный процесс перемешивания последней обеспечивает гашение теплового действия высокотемпературных импульсов и возможных побочных экзотермических процессов: В результате создаются условия для ведения процесса деструкции при низкой температуре в реакционном пространстве с подавлением термоинициируемых вторичных реакций.

Ограниченные рамки статьи не позволяют уделить в ней должное внимание анализу возможных в этих условиях вторнчных явлений и охарактеризовать механнзм физических процессов, сопутствующих высоковольтному пробою жидкостей и описанных в соответствующей литературе $\left[{ }^{15-17}\right]$.

\section{Методика и результаты исследования}

Объектом исследования явился сланец-кукерсит (смесь материала из слоев $\mathrm{A}-\mathrm{F}$ шахты «Кивиыли»), измельченный под сито № 100 и обогащенный центрсбежным способом до содержания органического вещества $\mathrm{O}^{\mathrm{c}}=89-90 \%$. В одном случае обогащение производилась: стмывкой соляной кислотой $1: 10$ на холоду (опыты серий $2-7$ )*. Характеристика исходного продукта, использованного в опытах серий 3 и 8. приведена в табл. 1. В первом случае кероген сланца, подвергшегося незначительному естественному выветриванию, содержит несколько повышенное против нормы количество кислорода. В качестве

* Концентрат сланца, нспользованный в опытах серий 1 и 8 , любезно предоставлен кандидатом технических наук А. С. Фоминой. 
вмещающей жидкости в этих опытах использована дистиллированная вода.

Опыты проведены в герметичном металлическом реакторе емкостью около 3 л. Количество обогащенного сланца, последовательно обрабатываемого в одной серии опытов, составляло 200-400 г. В каждой серии после подачи определенного количества импульсов высокого напряжения (с автоматической регистрацией их специальным счетчиком) отбирались пробы газа (в резиновый газгольдер), твердого материала и жидкости. В ходе опытов систематически измерялись: температура среды, давление в подсводовой части реактора, величина электросопротивления между электродами. Для подачи импульсов использована установка, принципиальная схема которой описана в работах $\left[{ }^{10,1}\right]$. Она позволяет с достаточной гибкостью варьировать электрические параметры процесса.

Таблица 1

Характеристика суммарного твердого продукта и газа

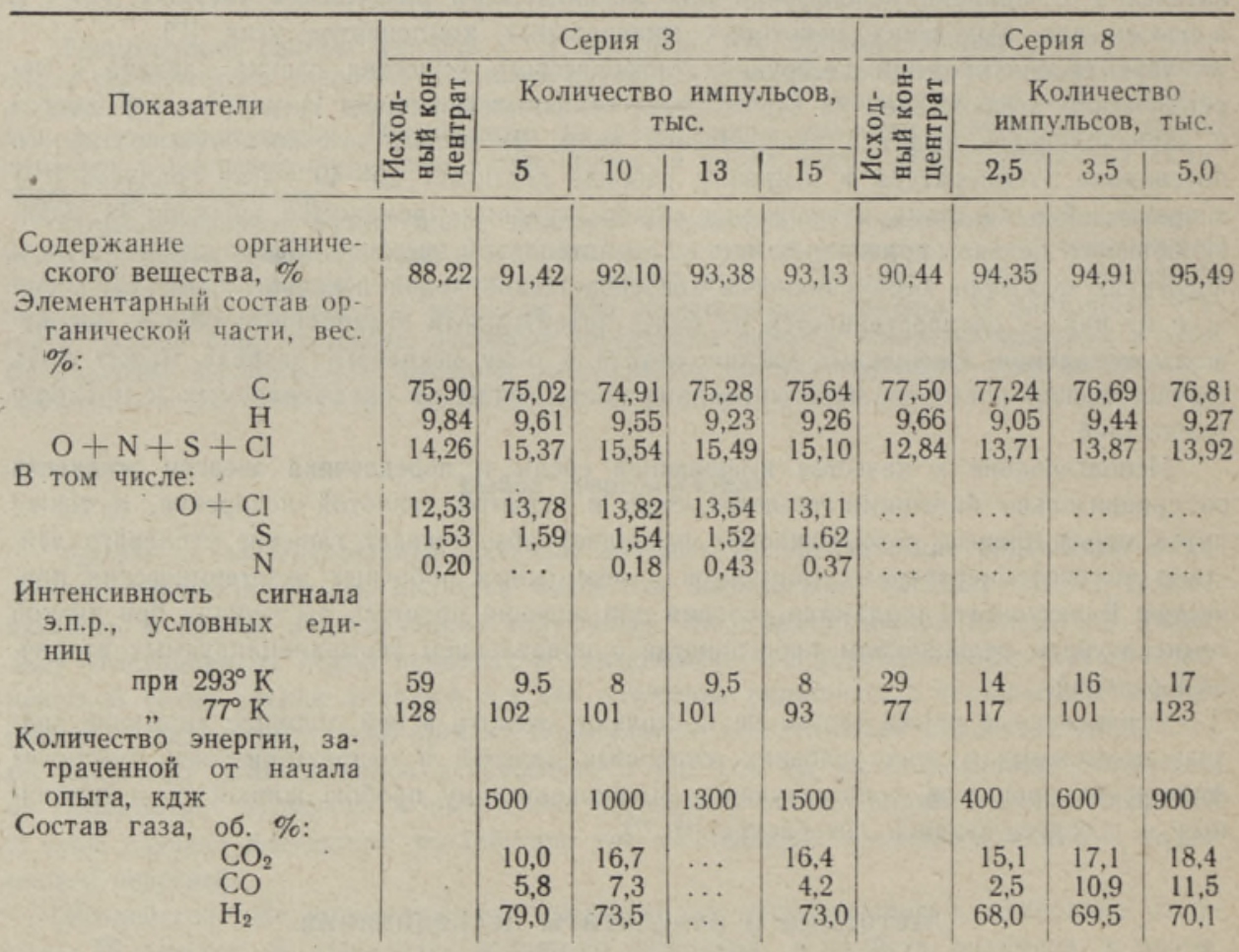

При мечание. Энергия единнчного импульса в опытах серни $3-100$ дж, серин 8-200 дж. Средняя мощность в опытах серии $3-0,1$ квт, серии $8-0,134$ квт.

Основными продуктами деструкции сланца являются газ и тонкодисперсный порошок несколько более темной, чем исходный концентрат, окраски. Состав газа исследован на хромотермографе и приборе ВТИ-2 и в ходе опытов практически мало изменяется (табл. 1). Для уточнения возможных побочных источников выделения газа (элект. ролиз воды, деструкция изоляционного материала верхнего электрода) было дополнительно проведено два «холостых» опыта с организацией разряда в воде без загрузки сланца. В результате подачи 2000 импульсов в этом случае выделилось практически незначительное (не более 
100 мл) количество газа. Состав последнего приводится ниже в сопоставлении с характеристикой газа, полученного в сходных условиях в опыте № 1 серии 8 при наложении всего 1000 импульсов:

\begin{tabular}{|c|c|c|c|c|c|}
\hline Состав газа, об. \% & $\mathrm{CO}_{2}$ & $\mathrm{CO}$ & $\mathrm{O}_{2}$ & $\mathrm{H}_{2}$ & $\mathrm{~N}_{2}$ \\
\hline $\begin{array}{l}\text { Холостой опыт № } 10 \\
\text { Опыт № } 1 \text { серии } 8\end{array}$ & $\begin{array}{l}8,5 \\
8,5\end{array}$ & $\begin{array}{r}4,5 \\
12,9\end{array}$ & $\overline{-}$ & $\begin{array}{l}40,4 \\
78,6\end{array}$ & $\underline{46,6}$ \\
\hline
\end{tabular}

Твердый продукт подвергается очистке от механических примесей, накапливающихся вследствие эррозии внутренней поверхности реактора. Характер последующего исследования твердого продукта деструкции определяется сформулированной выше целевой установкой настоящего этапа работы.

Изменение химического состава материала в зависимости от условий ведения процесса оценивается по результатам технического и элементарного анализа. Для ряда проб определено также содержание общей, сульфидной и органической серы, азота, различных форм железа в остатке минеральной части. Результаты основной части определений представлены в табл. 1.

Оценка структурно-химических превращений керогена в результате электрокавитационной обработки произведена с помощью спектров электронного парамагнитного резонанса (э.п.р.), снятых при различных температурах $\mathrm{T}_{\mathrm{c}}=293^{\circ} \mathrm{K}\left(+20^{\circ} \mathrm{C}\right)$ и $77^{\circ} \mathrm{K}\left(-196^{\circ} \mathrm{C}-\right.$ в жидком азоте). * Результаты, характеризующие интенсивность $I$ сигнала э. п. р., выраженную в условных сопоставимых единицах, представлены в табл. 1.

Примечательным свойством керогена кукерсита является значительная, инертность по отношению к любым растворителям. В связи с этим и с целью выделения относительно низкомолекулярного продукта деструкции, образцы твердого материала были подвергнуты обработке при комнатной температуре широким набором растворителей: этиловым и метиловым спиртом, уксусной кислотой, ацетоном, этиловым эфиром, диоксаном, дихлорэтаном, четыреххлористым углеродом, бензолом, пиридином, анилином и др., которая не дала визуально ощутимых результатов. Нагрев пробы с пиридином при $100^{\circ}$ приводит к окрашиванию жидкости; остаток после отгонки растворителя (весовой выход около $10 \%$ от исходного материала) представляет собой вязкую битумообразную массу (при комнатной температуре) коричневато-бурого цвета. Часть экстрагированного продукта легко растворима на холоду в воде (РН раствора 1:10 равен приблизительно 5,0) и уксусной кислоте, слабее - этаноле, анилине, бензоле. Поэтому все попытки определить молекулярный вес продукта криоскопическим методом не увенчались успехом. Для контроля произведена обработка исходного обогащенного сланца пиридином в тех же условиях. Выход экстрагируемого вещества составил всего $3,5 \%$. Оно полностью инертно по отношению к указанным выше растворителям и отличается от продукта деструкции элементарным составом. Результаты этой части исследования представлены в табл. 2.

* Названные нсследования проведены на установке Института нефтехимического синтеза АН СССР при участии Ю. Б. Эмина. Характеристика установки и методика исследования описаны в работах $[3,4]$. 
Характеристика продуктов, растворимых в пиридине

\begin{tabular}{|c|c|c|c|c|c|c|c|}
\hline \multirow{3}{*}{ Продукт } & \multirow{2}{*}{\multicolumn{4}{|c|}{$\begin{array}{c}\text { Элементарный состав, } \\
\text { вес. \% }\end{array}$}} & \multicolumn{3}{|c|}{ Атомные соотношения } \\
\hline & & & & & & $100 \mathrm{C}$ & \\
\hline & C & $\mathrm{H}$ & $\begin{array}{l}\mathrm{O}+\mathrm{N}+ \\
+\mathrm{S}+\mathrm{Cl}\end{array}$ & $\mathrm{S}$ & $\mathrm{H}$ & $\begin{array}{c}(\mathrm{O}+\mathrm{N}+ \\
+\mathrm{S})\end{array}$ & \\
\hline
\end{tabular}

Оп т с ерии $3, N=13,0$ тыс. импульсов

Исходный концентрат

Экстракт из исходного концентрата

Суммарный экстракт из обработанного концентрата

Нерастворимая в воде часть экстракта

Обработанный импульсами суммарный материал

\begin{tabular}{|c|c|}
75,90 & 9,84 \\
44,60 & 5,59 \\
46,37 & 6,16 \\
51,81 & 5,21 \\
74,91 & 9,55
\end{tabular}

14,26

49,81

47,47

42,98

15,44

\begin{tabular}{c|c|c}
1,53 & 155,5 & 14,05 \\
$\ldots$ & 150,0 & 83,70 \\
$\ldots$ & 159,5 & 75,30 \\
$\ldots$ & 120,5 & 62,40 \\
1,54 & 153,0 & 15,50
\end{tabular}

11,10

2,12

9,85

Оп т серии $8, N=6,0$ тыс. импульсов

Исходный концентрат

Экстракт из исходного кон центрата

Суммарный экстракт из обработанного концентрата Обработанный импульсами суммарный материал

\begin{tabular}{|l|l|l}
77,30 & 9,70 & 13,00 \\
45,14 & $5,(19$ & 49,77 \\
47,05 & 5,56 & 47,39 \\
76,94 & 9,70 & 13,36
\end{tabular}

\begin{tabular}{|c|c|c|}
$\ldots$ & 150,0 & 12,6 \\
$\ldots$ & 163,0 & 83,0 \\
$\ldots$ & 142,0 & 75,5 \\
$\ldots$ & 151,5 & 13,05
\end{tabular}

На заключительном этапе изучения свойств и состава продуктов деструкции были сняты спектры инфракрасного поглощения (и.к.п.) для суммарного вещества, экстрагируемого пиридином. Работа выполнена на модернизированном двухлучевом спектрографе [18] с призмами из фтористого лития и хлористого натрия путем нанесения раствора на кювету из бромистого калия с последуюшим удалением растворителя *. Спектры и.к.п. сняты И. Арро при участии Л. Паальме, расшифровка спектрограмм произведена авторами по данным монографии [21]. Результаты приведены в табл. 3 .

\section{Обсуждение результатов и выводы}

Результаты проведенного исследования свидетельствуют о протекании своеобразного процесса деструкции, по своему характеру и результатам резко отличающегося от термического разложения кукерсита. Последовательное их обсуждение позволяет составить определенное представление о механизме процесса и некоторых свойствах продуктоп электрокавитационной деструкции сланца.

Ранее было показано $[3,4]$, что кероген сланца кукерсита характеризуется узким однокомпонентным сигналом в спектре э.п.р. (фактор $g=2,002, \Delta H=0,6$ гаусса), интенсивность которого $I$ возрастает, а структура не изменяется с понижением температуры $T_{\text {c }}$ от 293 до $77^{\circ} \mathrm{K}$. Подобного рода сигналы свидетельствуют о наличии в исходном материале структур с полисопряженными двойными связями. При термической обработке сланца интенсивность сигнала в спектрах для твердого остатка при $T_{\mathrm{c}}=293^{\circ} \mathrm{K}$ резко возрастает в связи с увеличением

* Установка сектора физико-хнмнческих исследований Института химнн АН ЭССР, руководитель кандидат технических наук О. Эйзен. 
Результаты нсследования экстрагированного продукта с помощью спектра и.к.п.

\begin{tabular}{|c|c|c|}
\hline $\begin{array}{c}\text { Длина } \\
\text { волны } \\
\text { н.к.п. }\end{array}$ & $\begin{array}{l}\text { Интенсивность } \\
\text { полосы }\end{array}$ & Атомные группировки \\
\hline 11,65 & Слабая & $\begin{array}{c}\text { Алифатические связи типа }\left(\mathrm{CH}_{3}\right)_{3}-\mathrm{C}-\text {; } \\
\text { ароматические циклы, неконденсированные } \\
\text { с } 2-3 \text { алифатическими заместителями }\end{array}$ \\
\hline 12,40 & Слабая & $\begin{array}{l}\text { Алифатические звенья типа }\left(\mathrm{CH}_{3}\right)_{3}-\mathrm{C}-\text {; } \\
\text { простые алифатические циклические эфиры; } \\
\text { карбоксильная группа твердых жирных ки- } \\
\text { слот; простые ароматическне эфиры }\end{array}$ \\
\hline $\begin{array}{l}14,80 \\
14,90\end{array}$ & $\begin{array}{l}\text { Средняя } \\
\text { Слабая }\end{array}$ & $\begin{array}{l}\text { Метиленовые группы - } \mathrm{CH}_{2}-\text {; алифатиче- } \\
\text { скне концевые группы с четвертичным угле- } \\
\text { родом; скелетные связи С=С в неконден- } \\
\text { сированных замещенных ароматических цик- } \\
\text { лах }\end{array}$ \\
\hline $1 \overline{5}, 40$ & Сильная & Карбоксильная группа С \\
\hline 16,15 & Выше средней & $\begin{array}{l}\text { B-ненасыщенные гидпоксикетоны } \\
\text { Все виды связей C=C *; ассоциированные } \\
\text { группы C=O; карбоксильная группа; заме- } \\
\text { щенные ароматические циклы }\end{array}$ \\
\hline 16,45 & Средняя & $\begin{array}{l}\text { Несопряженные связи С }=\text { в в алифатических } \\
\text { цепочках; дикетоны (энольные); ненасы- } \\
\text { щенные гидроксикетоны, возможно, такне } \\
\text { же альдегиды }\end{array}$ \\
\hline 17,15 & Сильная & $\begin{array}{l}\text { Ненасыщенные алифатические кетоны, кисло- } \\
\text { ты, альдегиды; шести-семичленные цикли- } \\
\text { ческие алифатические кетоны; ненасыщен- } \\
\text { ные кислоты }\end{array}$ \\
\hline 28,25 & Средняя & $\begin{array}{l}\text { Гидроксильная группа ассоцинрованная; воз- } \\
\text { можно, метиленовая группа }-\mathrm{CH}_{2}-\end{array}$ \\
\hline $\begin{array}{l}29,25 \\
30,50\end{array}$ & $\begin{array}{l}\text { Сильная } \\
\text { Слабая }\end{array}$ & $\begin{array}{l}\text { Алифатические } \quad \text { ненасышенные } \quad \text { связи } \\
\mathrm{CH}_{2}=\mathrm{CH}-; \quad \mathrm{CH}=\mathrm{CH}<; \quad \mathrm{CR}_{1} R_{2}=\mathrm{CH} R_{3} ; \\
\text { гидроксильная группа ассоциированная }\end{array}$ \\
\hline
\end{tabular}

* В том числе сопряженные алифатические связи >C= $-\mathrm{C}=\mathrm{C}<$

размеров конденсированных полисопряженных структур под воздействием температуры.

В данном же случае, в итоге электрокавитационной обработки сланца, интенсивность сигнала э.п.р. в спектрах, снятых также при комнатной температуре, значительно снижается по сравнению с $I$ для исходного концентрата (табл. 1). Это обстоятельство, наряду с неизменной тенденцией к увеличению $I$ при снижении $T_{\text {c }}$ до $77^{\circ} \mathrm{K}$ без изменения структуры сигнала, является признаком существенной по глубине деструкции макромолекулы керогена без образования конденсированных структур.

K сходному заключению приводит также изменение элементарного состава твердого продукта. Под воздействием электрокавитационной обработки органическое вешество обогашается кислородом и азотом, несколько обедняется углеродом и, особенно, водородом. Состав газа в известной мере соответствует указанным изменениям в составе твердого остатка. Таким образом, суммарным конечным эффектом электрокавитационной деструкции является более активное протекание прошессов относительной декарбонизации и дегидрирования по срав- 
нению с дезоксидацией. Напомним, что на ранних стадиях термического разложения кукерсита наблюдается обратная картина.

Механизм деструкции сланца в результате электрокавитационной обработки при известной схематизации можно представить в следующем виде. Как известно, кероген кукерсита представляет собой природное высокомолекулярное вещество сложного строения и сравнительно гомогенного состава. «Первичная» структурная единица макромолекулы обладает значительными размерами и молекулярным весом (предположительно 3000-5000). Она характеризуется полисопряженными двойными связями, органически включенными гетероатомами, ассоциированными кислородными и сернистыми функциональными группами и эфирными связями, природа которых не вполне установлена $\left[{ }^{1,3}\right]$. Наличие системы сопряженных двойных связей определяет специфику деструкции керогена: распад макромолекулы происходит с диспропорционированием образующихся бирадикалов $\left[{ }^{5,19}\right]$ и приводит к значительному выходу «мономера», находящегося в твердом агрегатном состоянии; в «мономерных» звеньях имеются, наряду с весьма устойчивыми структурами, резко ослабленные связи (у атома углерода, находящегося в $\beta$-положении относительно двойной связи). Энергия разрыва последних ( $~ 60$ ккал/моль) существенно ниже, чем для обычных углерод-углеродных и углерод-кислородных связей (например, в соединениях типа $R-\mathrm{OH}$ около 90 и не менее 70 ккал/моль) [20].

При термическом разложении кукерсита, в силу неизбежной неизотермичности системы, находящейся в твердом агрегатном состоянии, и локальных перегревов, более энергоемкий процесс дезоксидации протекает не менее активно, чем разрыв углеродных цепочек. В рассматриваемом случае энергия подводится к каждой из частиц более равномерно, процесс деструкции протекает в более строгой энергетической последовательности и разрыву подвергаются только наименее стойкие из гетероатомных связей (например, находящиеся в указанном ослабленном состоянии в $\beta$-положении к двойной связи).

Побочными химическими процессами в данных условиях могут явиться: окисление продуктов распада и даже окислительная деструкция значительных обрывков полимерной цепи атомарным кислородом, выделяющимся при электролизе воды и под действием кавитации; взаимодействие образующихся под действием разряда ионов и свободных радикалов $\mathrm{OH}^{*}$ с керогеном и продуктами его деструкции. Оба эти процесса протекают в пространственно ограниченной зоне (примыкающей к зоне искрового разряда) и могут иметь лишь локальное значение.

Указанные соображения относятся, естественно, к деструкции при сравнительно невысоком (см. примечания к табл. 1) энергетическом уровне системы, характерном для опытов серий 3 и 8. Данные табл. 1 свидетельствуют о том, что изменение состава и химической структуры твердого продукта зависит не только от количества затраченной энергии $W_{\varepsilon}$ и числа импульсов $N$, но и от величины энергии единичного импульса и подводимой мощности. При данных физических параметрах изменение $W_{\text {c }}$ и $N$ мало отражается на показателях элементарного состава и интенсивности сигнала э.п.р.

Приведенные в табл. 2 и 3 результаты исследования продуктов деструкции, особенно экстрагируемых компонентов, подтверждают сформулированные представления о механизме процесса. Растворимый в пиридине продукт содержит значительное количество кислорода (от 45 до $49 \%$ ), что лишь отчасти можно приписать воздействию вторичных окислительных реакций. Он представляет собой смесь сравнительно низкомолекулярных веществ, спектр и.к.п. для которой (при описанной 
методике спектрального исследования) дает только общее представление о структуре входящих в ее состав соединений. Характерными особенностями последних являются: наличие метиленовых цепочек сравнительно небольшой длины, углеродных цепочек с двойными связями, возможно, входящих в состав неконденсированных ароматических ядер. Из кислородных функций можно указать на наличие карбонильных (кетонных) и, возможно, карбоксильных и гидроксильных групп. Весьма примечательным является отсутствие в спектре и.к.п. полос, соответствующих колебаниям C-H- и C-O-связей для фенолов и ароматических сложных эфиров.

Таким образом, можно полагать, что продукт деструкции представляет собой смесь кетонов и кислот или альдегидов смешанного, алифатического и ароматического характера; он, по-видимому, сохраняет генетическую связь с исходным керогеном в большей мере, чем продукты термического разложения последнего. Детальное изучение состава, свойств и возможностей использования продуктов электрокавитационной деструкции сланца является одной из задач дальнейшего исследования в описанном направлении.

В заключение авторы приносят свою искреннюю благодарность доктору физико-математических наук Л. С, Полаку и кандидату технических наук О. Эйзену за предоставленную им возможность спектрального исследования продуктов деструкции.

\section{Л И Т Р А Т Р Р А}

1. М. Я. Губергриц, Влияние условий нагрева на распределение продуктов при термическом разложении сланца-кукерсита, Изв. АН ЭССР. Серия физ.-мат. н техн. наук, т. IX, № 4, 1960.

2. М. Я. Губергриц, Л. П. Па альме, М. А. М аргусте, Распределение углеводородных компонентов в газе термического разложения сланца-кукерсита, Сб. Горючие сланцы. Химия и технология, вып. 4, 1961 (в печати).

3. М. Я. Гу бергриц, Б. Х. Бродская, Л. П. Па альме, К. А. Куйв, Структурно-химические превращения при термическом разложении сланца-кукерсита, Сб. Горючие сланцы. Химия и технология, вып. 4, 1961 (в печати).

4. М. Я. Губергриц, Л. С. Полак, Б. Х. Бродская, К. А. Куйв, Ю. Б. Э м и н, Спектры электронного парамагнитного резонанса в прибалтийских горючих сланцах, Докл. АН СССР, т. 136, № 4, 1961

5. Ф. Бовей, Действие ионизирующих излучений на природные и синтетические полимеры, М., ИЛ, 1959.

6. Л. Бе ргм ан, Ультразвук, М., ИЛ, 1956.

7. Ю. Б. Тют юн н и ов, Применение токов высокой частоты для нагрева угольных формовок в стадии испытания, Кокс и химия, № 12, 1957.

8. Ю. Л. С ев астьянов, Н. Н. Долго полов, и др, Изменение электрических характеристик при тепловом и диэлектрическом нагреве угля, Докл. АН СССР, т. $74, № 4,1950$. 9. Ф. Д а н и э л с, Высокотемпературная химия, Сб. Новая химия, М., Изд. АН СССР,

10. Б. Х. Бр одская, Изучение процесса электросбойки сланцевых пластов, Сб. Горючие сланцы. Химия и технология, вып. 1, 1954.

11. Б. Х. Бр одская, Лабораторные исследования процесса образования первоначального канала электросбойки, Гл. 4 монографии «Применение электрического тока для непосредственного воздействия на пласт топлива при бесшахтной подземной газифнкации», М., Изд. АН СССР, 1959.

12. Л. А. Юткин, Электрогидравлическое дробление, Л., 1959.

13. Б. И. Л осе в и др., Новые методы изучения вещественного состава углей, Вестн. AH CCCP, № 10, 1958. 
14. И. Е. Б а лыгин, О температуре искры при пробое жидких диэлектриков, Инженерно-физич. ж., № 8, 1960.

15. Т. В. Ба жен ов а, Р. И. Солоухин, Поле давлений, возникающее в воде при электрическом разряде, Сб. Физическая гидродинамика, М., Изд. АН СССР, 1959.

16. И. Е. Балыгин, Некоторые закономерности электрического пробоя жидких диэлектриков, Изв. АН СССР. Серия физич. наук, т. 22, № 4, 1958.

17. И. А. Р ой, Д. П. Ф ролов, Об электроакустическом к. п. д. искрового разряда в воде, докл. АН СССР, т. 118, № 4, 1958.

18. В. А. Ион сон, К. Р. А рн о ве ер, Модернизированный спектрограф ИКС-12 на базе полупроводникового датчика, Сб. Горючие сланцы. Химия и технология, вып. 4 (в печати).

19. Н. Г расс и, Химия процессов деструкции полимеров, М., ИЛ, 1959.

20. Н. Н. С емен ов, О некоторых проблемах химической кинетики и реакционной способности, М., Изд. АН СССР, 1958.

21. L. J. B ell a m y, The infra-red spectra of complex molecules, London, 1958.
Институт химии
Академии наук Эстонской ССР
Поступнла в редакцию
14. III 1961

\title{
KUKERSIIDI DESTRUKTSIOON SÄDELAHENDUSE PUHUL VEDELAS KESKKONNAS
}

\author{
M. Gubergrits, B. Brodskaja, L. Paalme, \\ tehniliste teaduste kandidaadid \\ K. Kuiv \\ Resümee
}

Kukersiidi termilisel lagunemisel on suur tähtsus temperatuurist tingitud sekundaarsetel protsessidel, mille tulemuseks on suur raskete kondenseeritud produktide saagis. Nimetatud produkte aga ei sobi kasutada keemiatööstuses toorainena.

Antud uurimistöö eesmärgiks oli valida energiakandja, mis lubaks kukersiidi orgaanilist ainet destrueerida vōimalikult madalal temperatuuril. Selliste energiakandjate, nagu ioniseeriv kiirgus, ultraheli ja kõrgsagedusega elektrivälja võrdleva hindamise tulemusena valiti destruktsiooniprotsessiks kõrgepingelise läbilöögi korral vedelas dielektrikus eralduv energia.

Kompleksse füüsikalis-keemilise uurimise alusel selgitati välja, et niisugusel elektriliskavitatsioonilisel töötlemisel toimub pōlevkivi kerogeeni destruktsioon, mille mehhanism ja 1ulemused termiiise lagunemise protsessiga vōrreldes on tunduvalt erinevad.

Destruktsiooniproduktideks on gaas ia peendispersne pulber. Viimase ekstraheerimisel aluseliste orgaaniliste lahustajatega (püridiin) eraldati madala molekulkaaluga produktid, millel tõenäolise keemilise valemi $\left(\mathrm{C}_{8} \mathrm{H}_{11} \mathrm{O}_{6}\right)_{n}$ puhul on happeline iseloom.
Eesti NSV Teaduste Akadeemia Keemia Instituut
Saabus toimetusse
14. III 1961

\section{KUKERSITE OIL-SHALE DESTRUCTION UNDER SPARK DISCHARGE IN A LIQUID}

\author{
M. Gubergrits, B. Brodskaya, L. Paalme, K. Kuiv
}

\section{Summary}

The thermal decomposition of Estonian oil-shale kukersite is accompanied by some active secondary thermoinitiated reactions resulting in high yields of heavy condensed products (heavy tar, coke residue). This paper deals with the choice and principal evaluation of the utilization of some energy-carriers making possible the kerogen destruction under relatively low temperatures with an elimination of the beforementioned secondary effects. 
Thus a method of kerogen destruction is chosen applying the energy of a spark discharge in a liquid. In that case the main factors effecting the destruction process are: 1) ultrasonic waves and cavitation effect of high intensity; 2) a stream of charged elementary particles; 3) thermal impulses causing a local temperature rise to order of 20 to 40 thousand degrees $\mathrm{C}$.

The results of the experimental investigation show a great difference in the mechanism and products characteristic both of the kerogen liquid spark discharge destruction and thermal decomposition processes. The pyridine-soluble products of the above-mentioned oil-shale kerogen destruction are of a high oxygen content and present interesting material for a further chemical synthesis.

Academy of Sciences of the Estonian S.S.R., Institute of Chemistry

Received March 14th, 1961 